\title{
Pengaruh Pelican Crossing terhadap Panjang Antrian dan Tundaan Kendaraan di Ruas Jalan Asia Afrika Kota Bandung
}

\author{
MUHAMMAD REZA NUGRAHA, DWI PRASETYANTO, ANDREAN MAULANA
}

\author{
Jurusan Teknik Sipil Institut Teknologi Nasional \\ Email: mrezangrh@gmail.com
}

\begin{abstract}
ABSTRAK
Pelican crossing merupakan jenis penyeberangan yang dioperasikan oleh penyeberang jalan yang bertujuan memberikan keselamatan kepada penyeberang. Tujuan dari penelitian ini adalah menentukan jenis penyeberangan dan mencari pemodelan tundaan dan panjang antrian akibat pelican crossing di jalan Asia Afrika Bandung. Data penelitian ini adalah frekuensi penyeberangan, jumlah penyeberang, jumlah kendaraan terhenti, arus lalu lintas, tundaan dan panjang antrian kendaraan. Analisis penentuan jenis penyeberangan menggunakan perhitungan $\mathrm{PV}^{2}$ dan analisis pemodelan tundaan dan panjang antrian menggunakan regresi linier berganda. Dari perhitungan $\mathrm{PV}^{2}$ didapatkan hasil $P V^{2}=2,49 * 10^{9}$ yang berarti termasuk kepada jenis penyeberangan pelikan dengan lapak tunggu. Model yang mewakili hubungan antara panjang antrian $(Y)$ dengan jumlah kendaraan terhenti $\left(X_{1}\right)$ dan frekuensi penyeberangan $\left(X_{2}\right)$ adalah $Y=2,201+3,203 X_{1}+3,510 X_{2}$. Model yang mewakili hubungan antara tundaan $(Y)$ dengan variabel bebas yang sama adalah $Y=0,709+2,656 X_{1}+7,645$. Panjang antrian maksimum sebesar 78,072 meter dan tundaan maksimum sebesar 89,826 detik.
\end{abstract}

Kata kunci: pelican crossing, panjang antrian, tundaan

\begin{abstract}
Pelican crossing is a type of pedestrian cross which is operated by pedestrian with purpose is to give safety for the crosser. The aim of this study are to determine the type of crossing and find the model of delay and queue length because of pelican crossing at Asia Afrika Street Bandung. The data of this study are crossing frequency, amount of crossers, amount of stopped vehicle, traffic flow, delay and queue length vehicle. Analysis for the type of the crossing obtained by calculation of $P^{2}$ and analysis of model delay and queue length are use multiple regression. The result from the calculation of $\mathrm{PV}^{2}$ is $P V^{2}=2,49 * 10^{9}$ which is the type of the crossing is pelican with protector. The represent model of relation between the queue length $(Y)$ with amount of stopped vehicle $\left(X_{1}\right)$ and crossing frequency $\left(X_{2}\right)$ is $Y=2,201+3,203 X_{1}+3,510 X_{2}$. The represent model of relation between delay $(Y)$ with same dependent variable is $Y=0,709+2,656 X_{1}+7,645$. The maximum queue length is 78,072 meters and the delay maximum is 89,826 seconds.
\end{abstract}

Keyword: pelican crossing, the queue length, delay 


\section{PENDAHULUAN}

Jalan Asia Afrika merupakan jalan yang memiliki arus lalu lintas tinggi karena berada di kawasan kegiatan perkonomian dan pariwisata Kota Bandung. Berbagai kegiatan manusia di kawasan jalan Asia Afrika dapat menimbulkan permasalahan lalu lintas. Fasilitas pelican crossing disediakan untuk memberikan keselamatan pada penyeberang jalan. Permasalahan yang timbul adalah jika arus frekuensi penyeberangan sedang tinggi, maka akan menimbulkan tundaan dan antrian kendaraan. Oleh karena itu, dalam penelitian ini akan ditinjau mengenai tundaan dan panjang antrian kendaraan akibat pelican crossing.

Tujuan dari penelitian ini adalah untuk menentukan jenis penyeberangan menggunakan perhitungan $P V^{2}$ dan mencari pemodelan tundaan dan panjang antrian pada lajur kendaraan menggunakan analisis regresi linier berganda.

\section{TINJAUAN PUSTAKA}

\subsection{Pelican Crossing}

Pelican crossing (Pedestrian Light Controlled Crossing) adalah suatu fasilitas untuk penyeberangan pejalan kaki sebidang yang dilengkapi dengan marka dan lampu pengatur lalu lintas. Penyeberangan jenis ini biasanya dilengkapi dengan tombol untuk mengaktifkan lampu lalu lintas. Bila tombol ditekan, maka beberapa saat kemudian lampu untuk pejalan kaki menjadi hijau dan lampu menjadi merah untuk kendaraan (Departemen Pekerjaan Umum, 1999).

\subsection{Arus Lalu Lintas}

Arus lalu lintas merupakan interaksi yang unik antara pengemudi, kendaraan dan jalan. Model ini adalah model yang paling awal dalam mengamati perilaku lalu lintas. Menurut PKJI, 2014, Jumlah kendaraan bermotor yang melalui suatu titik pada suatu penggal jalan per satuan waktu yang dinyatakan dalam satuan kend/jam, atau skr/jam $\left(Q_{\text {kend }}\right)$, atau skr/hari (LHRT). Dalam penelitian ini, yang dimaksud arus lalu lintas adalah jumlah kendaraan yang terhenti pada saat lampu penyeberangan pejalan kaki menjadi merah untuk kendaraan. Data yang didapat akan dikonversikan menjadi ekivalen kendaraan ringan (Kementerian Pekerjaan Umum, 2014). Nilai ekivalen kendaraan ringan dapat dilihat pada Tabel 1.

Tabel 1. Nilai Ekivalen Kendaraan

\begin{tabular}{cc}
\hline Jenis Kendaraan & EKR \\
\hline Kendaraan Ringan (KR) & 1,0 \\
\hline Kendaraan Berat (KB) & 1,2 \\
\hline Sepeda Motor (SM) & 0,25
\end{tabular}

(Sumber: Kementerian Pekerjaan Umum, 2014)

\subsection{Penentuan Fasilitas Penyeberangan}

Untuk menentukan suatu jenis penyeberangan dibutuhkan data mobilitas dari suatu ruas jalan tersebut agar dapat diketahui fasilitas apa yang harus digunakan pada ruas jalan tersebut (Departemen Pekerjaan Umum, 1999). Yang membedakan kapan menggunakan fasilitas tersebut yaitu berikut: 
1. Penyeberangan Sebidang

Kriteria yang dapat digunakan dalam memilih fasilitas penyeberangan pedestrian sebidang didasarkan pada perhitungan $P V^{2}$ dengan:

$P=$ arus pejalan kaki yang menyeberang pada ruas jalan setiap 1 jam (orang/jam),

$V=$ arus lalu lintas kendaraan setiap jam (kendaraan/jam).

Dari nilai $P V^{2}$ dapat direkomendasikan jenis fasilitas penyeberangan pejalan kaki yang dapat digunakan. Pemilihan jenis penyeberangan dapat dilihat pada Tabel 2.

Tabel 2. Rekomendasi Jenis Penyeberangan Sebidang

\begin{tabular}{cccc}
$\boldsymbol{P V}^{\mathbf{2}}$ & $\begin{array}{c}\boldsymbol{P} \\
\text { (Orang/jam) }\end{array}$ & $\begin{array}{c}\boldsymbol{V} \\
\text { (Kendaraan/jam) }\end{array}$ & Rekomendasi \\
\hline$\leq 10^{8}$ & & & Tidak Perlu Ada Penyeberangan \\
$>10^{8}$ & $50-100$ & $300-500$ & Zebracross \\
\hline $2 * 10^{8}$ & $50-1100$ & $400-750$ & Zebracross dengan lapak tunggu \\
$>10^{8}$ & $50-1100$ & $>500$ & Pelikan \\
$>10^{8}$ & $>1100$ & $>500$ & Pelikan \\
$>2 * 10^{8}$ & $50-1100$ & $>700$ & Pelikan dengan lapak tunggu \\
$>2 * 10^{8}$ & $>1100$ & $>400$ & Pelikan dengan lapak tunggu \\
\hline
\end{tabular}

(Sumber: Departemen Pekerjaan Umum, 1999)

2. Penyeberangan Tidak Sebidang

Fasilitas penyeberangan orang tidak sebidang ditempatkan sesuai dengan kriteria berikut:

a) Pada ruas jalan dengan kecepatan di atas $75 \mathrm{~km} / \mathrm{jam}$;

b) Pada kawasan-kawasan strategis di mana penyeberang tidak memungkinkan untuk penyeberangan jalan kecuali hanya pada jembatan;

c) $P V^{2}>2 * 10^{8}$ dengan $P>1100$ orang/jam dan $V>750 \mathrm{kend} / \mathrm{jam}$.

\subsection{Panjang Antrian Kendaraan}

Antrian didefinisikan sebagai jumlah kendaraan yang antri dalam suatu pendekat simpang yang dinyatakan dalam kendaraan atau satuan mobil penumpang, sedangkan panjang antrian didefinisikan sebagai antrian kendaraan dalam suatu pendekat dan dinyatakan dalam satuan meter (Kementerian Pekerjaan Umum, 2014).

\subsection{Tundaan Kendaraan}

Tundaan akibat hentian (stopped delay) adalah tundaan yang terjadi pada kendaraan dimana kendaraan tersebut berada pada kondisi benar-benar berhenti pada kondisi mesin masih hidup (Permana, 2013). Kondisi ini apabila berlangsung lama akan mengakibatkan kemacetan. Prinsip dari metode ini adalah suatu prosedur input dan output dengan stopped delay $\left(T_{s}\right)$ yang dihitung dengan Persamaan 1.

$$
T_{S}=\sum_{\mathrm{i}=1}^{\mathrm{n}}\left(A_{i}-D_{i}\right)
$$

halmana:

$T_{S} \quad=$ stopped delay (detik),

$n \quad=$ total kendaraan yang berhenti (kendaraan),

$A_{i} \quad=$ waktu ketika kendaraan terakhir dalam antrian mulai bergerak (detik),

$D_{i} \quad=$ waktu ketika kendaraan pertama dalam antrian mulai berhenti (detik). 


\subsection{Analisis Regresi Linear}

Analisis regresi-linear adalah metode statistik yang dapat digunakan untuk mempelajari hubungan antarsifat permasalahan yang sedang diselidiki. Model analisis regresi-linear dapat memodelkan hubungan antara dua variabel atau lebih. Tujuan utama analisis regresi adalah untuk melakukan pengujian antara variabel tidak bebas $(Y)$ dengan variabel bebas $(X)$ yang ditampilkan dalam bentuk persamaan regresi. Jika variabel tidak bebas $(Y)$ dihubungkan dengan satu variabel tidak bebas $(X)$, maka persamaan regresi yang dihasilkan adalah regresi linier sederhana (Tamin, 2000). Jika variabel tidak bebas $(Y)$ dihubungkan dengan dua buah atau lebih variabel bebas $(X)$, maka persamaan regresi yang dihasilkan adalah regresi linier berganda. Regresi linier sederhana $Y$ atas $X$ dapat dilihat pada Persamaan 2.

$$
Y=A+B X
$$

halmana:

$Y \quad=$ variabel tidak bebas,

$A=$ konstanta regresi,

$B=$ koefisien regresi,

$X \quad=$ variabel bebas.

Koefisien $A$ dan $B$ dapat dihitung dengan Persamaan 3 dan Persamaan 4.

$$
\begin{gathered}
B=\frac{\mathrm{n} \sum \mathrm{XY}-\left(\sum \mathrm{X}\right)\left(\sum \mathrm{Y}\right)}{\mathrm{n} \sum \mathrm{X}^{2}-\left(\sum \mathrm{X}\right)^{2}} \\
A=\bar{Y}-B \bar{X}
\end{gathered}
$$

Adapun regresi linier berganda $Y$ atas $X_{1}, X_{2}, \ldots, X_{k}$, dapat dilihat pada Persamaan 5.

$$
Y=A+B_{1} X_{1}+B_{2} X_{2}+\ldots+B_{k} X_{k}
$$

halmana:

$Y \quad=$ variabel tidak bebas,

$A \quad=$ konstanta regresi,

$B_{k} X_{k} \quad=$ koefisien regresi,

$X_{1} \ldots X_{k}=$ variabel bebas.

Suatu model memiliki hasil yang baik apabila memiliki kriteria sebagai berikut:

1. Semakin banyak peubah bebas yang digunakan, semakin baik model tersebut.

2. Tanda koefisien regresi (+/-) sesuai dengan yang diharapkan.

3. Nilai konstanta regresi kecil (semakin mendekati nol, semakin baik).

4. Nilai koefisien determinasi $\left(r^{2}\right)$ besar (semakin mendekati satu, semakin baik).

\subsection{Analisis Koefisien Korelasi}

Analisis koefisien korelasi ini dilakukan untuk memenuhi persyaratan model matematis sesama variabel bebas tidak boleh saling berkorelasi (Tamin, 2000), sedangkan antara variabel tidak bebas dengan variabel bebas harus ada korelasi yang kuat (baik positif maupun negatif). Nilai koefisien korelasi dapat dihitung dengan menggunakan Persamaan 6.

$$
r=\frac{\mathrm{n} \sum \mathrm{XY}-\left(\sum \mathrm{X}\right)\left(\sum \mathrm{Y}\right)}{\sqrt{\left\{\mathrm{n} \sum \mathrm{X}^{2}-\left(\sum \mathrm{X}\right)^{2}\right\}\left\{\mathrm{n} \Sigma \mathrm{Y}^{2}-(\Sigma \mathrm{Y})^{2}\right\}}}
$$


halmana:

$r \quad=$ koefisien korelasi,

$Y \quad=$ variabel tidak bebas,

$X \quad=$ variabel bebas,

$n \quad=$ jumlah data.

\subsection{Analisis Koefisien Determinasi}

Dalam analisis korelasi terdapat suatu nilai yang disebut dengan koefisien determinasi. Koefisien determinasi disebut juga dengan koefisien penentu, karena varian yang terjadi pada variabel tidak bebas dapat dijelaskan melalui varian yang terjadi pada variabel bebas. Nilai koefisien determinasi berkisar $0<r^{2}<1$. Apabila nilai $r^{2}$ semakin kecil (mendekati 0), maka semakin kecil pengaruh variabel bebas terhadap variabel tidak bebasnya. Sebaliknya, apabila nilai $r^{2}$ semakin besar (mendekati 1 ), maka semakin besar pengaruh variabel bebas terhadap variabel tidak bebasnya (Tamin, 2000).

\subsection{Studi Terdahulu}

Penelitian ini dilakukan dengan acuan dari hasil beberapa studi terdahulu yang akan diperlukan sebagai bahan perbandingan. Perbandingan dengan studi terdahulu dapat dilihat pada Tabel 3.

\section{Tabel 3. Hasil Penelitian Terdahulu}

\begin{tabular}{|c|c|c|c|}
\hline No & Nama Peneliti & Judul Penelitian & Hasil Penelitian \\
\hline 1 & Gina Brigitha & $\begin{array}{l}\text { Kajian Pelican Crossing Di } \\
\text { Kota Surakarta, Bekasi (2012) }\end{array}$ & $\begin{array}{l}\text { Hasil perhitungan } P V^{2}=86,95 * \\
10^{8} \text {. Rekomendasi pemilihan jenis } \\
\text { penyeberangan adalah pelikan } \\
\text { dengan lapak tunggu. }\end{array}$ \\
\hline 2 & Fajar Permana & $\begin{array}{l}\text { Model Hubungan Antara } \\
\text { Tundaan Dan Panjang Antrian } \\
\text { Kendaraan Dengan Lama } \\
\text { Penutupan Pintu Perlintasan } \\
\text { Kereta Api Di Jalan Laswi Kota } \\
\text { Bandung (2013) }\end{array}$ & $\begin{array}{l}\text { Model tundaan rata-rata }(Y) \text { dan } \\
\text { yang mewakilki Jalan Ahmad Yani } \\
\text { ke Jalan Gatot Subroto adalah } \\
Y=44,354+0,768 X_{1}+3,140 X_{2} \\
\text { dengan } r^{2}=0,741 \text { dan dari Jalan } \\
\text { Gatot Subroto ke Jalan Ahmad } \\
\text { Yani adalah } Y=1,000+ \\
1,097 X_{1}+3,711 X_{2} \text { dengan } r^{2}= \\
0,731 \text {. Model panjang antrian } \\
\text { rata-rata }(Y) \text { dan yang mewakili } \\
\text { Jalan Ahmad Yani ke Jalan Gatot } \\
\text { Subroto adalah } Y=4,642+ \\
0,064 X_{1}+2,221 X_{2} \text { dengan } r^{2}= \\
0,655 .\end{array}$ \\
\hline
\end{tabular}

\section{METODE PENELITIAN}

Data yang digunakan pada penelitian ini adalah data primer yaitu data yang diperoleh dengan cara survei secara langsung di lapangan. Data primer pada penelitian ini meliputi geometrik jalan, frekuensi penyeberangan, jumlah penyeberang jalan, jumlah kendaraan terhenti, arus lalu lintas, tundaan dan panjang antrian kendaraan. Waktu pelaksanaan survei pada kondisi sibuk yang dianggap dapat mewakili mobilitas di jalan Asia Afrika dengan interval lima menit selama 4 jam. Surveyor diposisikan di tempat yang mudah untuk mengambil data kendaraan dan penyeberangan yang terjadi. Ketika terjadi penyeberangan, surveyor akan mulai mencatat data yang dibutuhkan. Data yang didapat lalu di analisis menggunakan perhitungan $P V^{2}$ untuk 
menentukan jenis penyeberangan dan regresi linier untuk pemodelan panjang antrian dan tundaan.

\section{HASIL PENELITIAN DAN PEMBAHASAN}

\subsection{Perhitungan dan Penyajian Data}

Penelitian ini dilakukan di jalan Asia Afrika Bandung pada hari Rabu tanggal 31 Mei 2017 menghasilkan data primer berupa data geometrik jalan, frekuensi penyeberang, jumlah penyeberang, arus lalu lintas, panjang antrian dan tundaan kendaraan yang selanjutnya akan diolah dan dilakukan perhitungan.

\subsubsection{Data Geometrik}

Data geometrik yang di dapat merupakan data panjang jalan yang ditinjau sepanjang $230 \mathrm{~m}$. Data lebar ruas jalan adalah $10 \mathrm{~m}$ dengan $2,5 \mathrm{~m}$ per lajurnya. Data geometrik jalan yang ditinjau dapat dilihat pada Gambar 1.

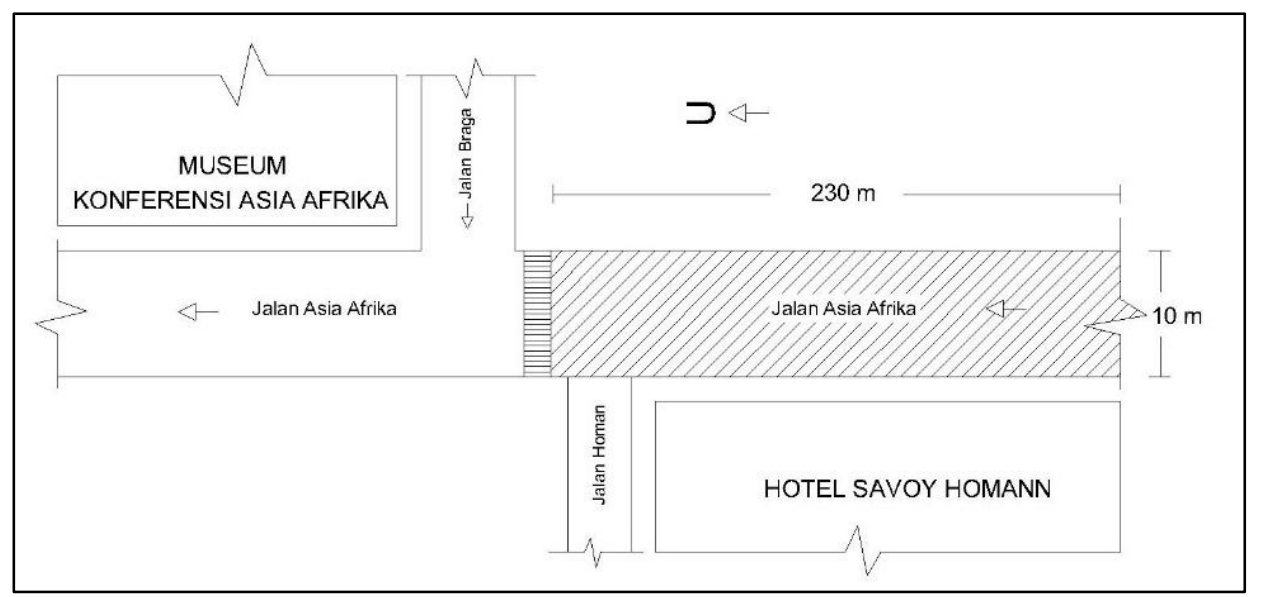

Gambar 1. Tampak atas lokasi survei

\subsubsection{Data Controller Pelican Crossing}

Pada pelican crossing dibutuhkan waktu tunggu untung menyeberang agar tidak menimbulkan frekuensi penyeberangan yang berlebih. Data waktu tunggu untuk menyeberang dapat dilihat pada Tabel 4.

Tabel 4. Data Waktu Tunggu untuk Menyeberang

\begin{tabular}{ccc}
\hline No. & $\begin{array}{c}\text { Jeda } \\
\text { Penyeberangan } \\
\text { (detik) }\end{array}$ & $\begin{array}{c}\text { Waktu } \\
\text { Tunggu } \\
\text { (detik) }\end{array}$ \\
\hline 1 & 0 & 98 \\
\hline 2 & 30 & 67 \\
\hline 3 & 45 & 54 \\
\hline 4 & 60 & 36 \\
\hline 5 & 75 & 28 \\
\hline 6 & 90 & 20 \\
\hline 7 & $>120$ & 4 \\
\hline
\end{tabular}




\subsection{Analisis Menentukan Jenis Penyeberangan}

Dari data survei yang sudah didapatkan selanjutnya dilakukan perhitungan $P V^{2}$ untuk menentukan jenis penyeberangan. Data yang dibutuhkan untuk perhitungan $P V^{2}$ dapat dilihat pada Tabel 5.

Tabel 5. Data Perhitungan $P V^{2}$

\begin{tabular}{ccc}
\hline Jam & $\begin{array}{c}\boldsymbol{P} \\
\text { (Pejalan kaki/jam) }\end{array}$ & $\begin{array}{c}\boldsymbol{V} \\
\text { (Kendaraan/jam) }\end{array}$ \\
\hline $\mathbf{0 7 . 0 0 - \mathbf { 0 8 . 0 0 }}$ & 85 & 5.044 \\
\hline $\mathbf{0 8 . 0 0}-\mathbf{0 9 . 0 0}$ & 79 & 4.782 \\
\hline $\mathbf{1 3 . 3 0}-\mathbf{1 4 . 3 0}$ & 102 & 4.764 \\
\hline $\mathbf{1 4 . 3 0}-\mathbf{1 5 . 3 0}$ & 104 & 4.898 \\
\hline
\end{tabular}

$$
\begin{aligned}
& P V^{2}=104 * 4.898^{2} \\
& P V^{2}=2.495 .002 .016 \\
& P V^{2}=2,49 * 10^{9}
\end{aligned}
$$

Berdasarkan Tabel 2, jenis penyeberangan yang sesuai dengan hasil perhitungan adalah penyeberangan pelikan dengan pelindung.

\subsection{Analisis Regresi Linier}

Analisis ini dilakukan untuk membuat model antara panjang antrian, tundaan, jumlah kendaraan terhenti dan frekuensi penyeberangan. Dalam penelitian ini digunakan analisis regresi linier berganda. Model regresi linier untuk panjang antrian dapat dilihat pada Tabel 6 dan Tabel 7. Model regresi linier untuk tundaan dapat dilihat pada Tabel 8 dan Tabel 9.

Tabel 6. Model Panjang Antrian

\begin{tabular}{lccc}
\hline Lajur & Persamaan & $\begin{array}{c}\text { Koefisien } \\
\text { Korelasi }\end{array}$ & $\begin{array}{c}\text { Koefisien } \\
\text { Determinasi }\end{array}$ \\
\hline 1 & $Y=2,201+3,203 X_{1}+3,510 X_{2}$ & 0,8 & 0,7 \\
\hline 2 & $Y=1,345+2,558 X_{1}+2,624 X_{2}$ & 0,7 & 0,5 \\
\hline 3 & $Y=2,145+2,271 X_{1}+7,138 X_{2}$ & 0,7 & 0,6 \\
\hline 4 & $Y=1,580+0,715 X_{1}+5,947 X_{2}$ & 0,8 & 0,6 \\
\hline halmana: & \\
$Y=$ panjang antrian kendaraan (meter), \\
$X_{1}=$ kendaraan yang terhenti (skr/5 menit), \\
$X_{2}=$ frekuensi Penyeberangan (penyeberangan/5 menit). \\
\hline
\end{tabular}

Tabel 7. Model Panjang Antrian Rata-rata

\begin{tabular}{ccc}
\hline Persamaan & $\begin{array}{c}\text { Koefisien } \\
\text { Korelasi }\end{array}$ & $\begin{array}{c}\text { Koefisien } \\
\text { Determinasi }\end{array}$ \\
\hline$Y=\mathbf{1 , 6 1 4}+\mathbf{2}, \mathbf{4 3 2} X_{1}+\mathbf{3}, \mathbf{7 0 9} X_{2}$ & 0,8 & 0,6 \\
\hline
\end{tabular}

halmana:

$Y=$ panjang antrian kendaraan rata-rata (meter),

$X_{1}=$ kendaraan yang terhenti rata-rata (skr/5 menit),

$X_{2}=$ frekuensi Penyeberangan (penyeberangan $/ 5$ menit). 
Tabel 8. Model Tundaan Kendaraan

\begin{tabular}{lccc}
\hline Lajur & Persamaan & $\begin{array}{c}\text { Koefisien } \\
\text { Korelasi }\end{array}$ & $\begin{array}{c}\text { Koefisien } \\
\text { Determinasi }\end{array}$ \\
\hline 1 & $Y=0,709+2,656 X_{1}+11,645 X_{2}$ & 0,8 & 0,6 \\
\hline 2 & $Y=0,033+1,892 X_{1}+11,368 X_{2}$ & 0,8 & 0,7 \\
\hline 3 & $Y=1,926+2,105 X_{1}+10,792 X_{2}$ & 0,7 & 0,6 \\
\hline 4 & $Y=0,020+1,301 X_{1}+8,021 X_{2}$ & 0,8 & 0,7 \\
\hline halmana: & & \\
$Y=$ tundaan kendaraan (detik), & \\
$X_{1}=$ kendaraan yang terhenti (skr/5 menit), & \\
$X_{2}=$ frekuensi Penyeberangan (penyeberangan/5 menit). & \\
\hline
\end{tabular}

Tabel 9. Model Tundaan Kendaraan Rata-rata

\begin{tabular}{lcc}
\hline \multicolumn{1}{c}{ Persamaan } & $\begin{array}{c}\text { Koefisien } \\
\text { Korelasi }\end{array}$ & $\begin{array}{c}\text { Koefisien } \\
\text { Determinasi }\end{array}$ \\
\hline $\mathrm{Y}=2,275+2,002 \mathrm{X}_{1}+8,359 \mathrm{X}_{2}$ & 0,8 & 0,6 \\
\hline halmana: & & \\
$Y=$ tundaan kendaraan rata-rata (detik), \\
$X_{1}=$ kendaraan yang terhenti rata-rata (skr/5 menit), \\
$X_{2}=$ frekuensi Penyeberangan (penyeberangan $/ 5$ menit). \\
\hline
\end{tabular}

Berdasarkan hasil yang diperoleh nilai koefisien determinasi lebih besar dari nol namun kurang dari satu. Hal ini menunjukan bahwa variabel bebas (jumlah penyeberang dan jumlah kendaraan terhenti) mempengaruhi besarnya tundaan yang terjadi pada kendaraan. Apabila tidak ada kendaraan yang terhenti $\left(X_{1}=0\right)$ dan tidak ada orang menyeberang $\left(X_{2}=0\right)$, antrian kendaraan akan tetap terjadi. Nilai koefisien korelasi lebih dari 0,5 berarti bahwa korelasi antara variabel positif. Nilai koefisien determinasi lebih dari 0,5 berarti bahwa variabel bebas memiliki pengaruh yang besar terhadap variabel tidak bebasnya.

\subsection{Analisis Pengaruh Pelican Crossing}

Setelah didapatkan pemodelan, selanjutnya akan dilakukan perhitungan pengaruh pelican crossing terhadap panjang antrian dan tundaan kendaraan. Data perhitungan pengaruh pelican crossing dapat dilihat pada Tabel 10. Hasil perhitungan dari pemodelan dapat dilihat pada Tabel 11 dan Tabel 12.

Tabel 10. Data Perhitungan Pengaruh Pelican Crossing

\begin{tabular}{cccc}
\hline & Lajur & $\begin{array}{c}\text { Jumlah Kendaraan } \\
\text { Terhenti } \\
\left(\boldsymbol{X}_{\mathbf{1}}\right)\end{array}$ & $\begin{array}{c}\text { Frekuensi } \\
\text { Penyeberangan } \\
\left(\boldsymbol{X}_{\mathbf{2}}\right)\end{array}$ \\
\hline & 1 & 20,4 & 3 \\
\hline \multirow{3}{*}{ Maks. } & 2 & 18,65 & 3 \\
\cline { 2 - 4 } & 3 & 18,65 & 3 \\
\hline & 4 & 12,7 & 3 \\
\hline \multirow{3}{*}{ Min. } & 1 & 1,75 & 1 \\
\cline { 2 - 4 } & 2 & 2 & 1 \\
\hline & 3 & 4 & 1 \\
\hline & 4 & 3 & 1 \\
\hline
\end{tabular}


Tabel 11. Hasil Perhitungan Panjang Antrian

\begin{tabular}{cccc}
\hline \multirow{2}{*}{ Lajur } & Persamaan & \multicolumn{2}{c}{ Panjang Antrian (m) } \\
\cline { 3 - 4 } & & Maks. & Min. \\
\hline 1 & $Y=2,201+3,203 X_{1}+3,510 X_{2}$ & 78,072 & 11,316 \\
\hline 2 & $Y=1,345+2,558 X_{1}+2,624 X_{2}$ & 56,923 & 9,085 \\
\hline 3 & $Y=2,145+2,271 X_{1}+7,138 X_{2}$ & 65,913 & 18,367 \\
\hline 4 & $Y=1,580+0,715 X_{1}+5,947 X_{2}$ & 28,501 & 9,672 \\
\hline
\end{tabular}

Tabel 12. Hasil Perhitungan Tundaan Kendaraan

\begin{tabular}{cccc}
\hline \multirow{2}{*}{ Lajur } & Persamaan & \multicolumn{2}{c}{ Tundaan (detik) } \\
\cline { 3 - 4 } & & Maks. & Min. \\
\hline 1 & $Y=0,709+2,656 X_{1}+11,645 X_{2}$ & 89,826 & 17,002 \\
\hline 2 & $Y=0,033+1,892 X_{1}+11,368 X_{2}$ & 69,422 & 15,185 \\
\hline 3 & $Y=1,926+2,105 X_{1}+10,792 X_{2}$ & 73,560 & 21,138 \\
\hline 4 & $Y=0,020+1,301 X_{1}+8,021 X_{2}$ & 40,606 & 11,944 \\
\hline
\end{tabular}

Berdasarkan hasil perhitungan didapatkan panjang antrian maksimum sebesar 78,072 meter dengan tundaan 89,826 detik. Panjang antrian minimum yang didapatkan sebesar 9,805 meter dengan tundaan sebesar 15,185 detik.

\section{KESIMPULAN DAN SARAN}

\subsection{Kesimpulan}

Dari hasil analisis dan pembahasan yang telah dilakukan maka dapat diambil kesimpulan sebagai berikut:

1. Berdasarkan perhitungan $P V^{2}$ hasil yang diperoleh sebesar 2.495.002.016 yang berarti jenis penyeberangan yang terpilih adalah pelikan dengan lapak tunggu. Namun harus mempertimbangkan juga faktor keamanan bagi pengendara jalan.

2. Model yang diperoleh untuk menggambarkan hubungan antara panjang antrian $(Y)$ dengan jumlah kendaraan yang terhenti $\left(X_{1}\right)$ dan frekuensi penyeberangan $\left(X_{2}\right)$ pada setiap lajur adalah sebagai berikut:

(a) pada lajur 1 persamaannya adalah $Y=2,201+3,203 X_{1}+3,510 X_{2}$ dengan koefisien determinasi 0,7 ;

(b) pada lajur 2 persamaannya adalah $Y=1,345+2,558 X_{1}+2,624 X_{2}$ dengan koefisien determinasi 0,5 ;

(c) pada lajur 3 persamaannya adalah $Y=2,145+2,271 X_{1}+7,138 X_{2}$ dengan koefisien determinasi 0,6 ;

(d) pada lajur 4 persamaannya adalah $Y=1,580+0,715 X_{1}+5,947 X_{2}$ dengan koefisien determinasi 0,6 .

3. Model yang diperoleh untuk menggambarkan hubungan antara tundaan kendaraan $(Y)$ dengan jumlah kendaraan yang terhenti $\left(X_{1}\right)$ dan frekuensi penyeberangan $\left(X_{2}\right)$ pada setiap lajur adalah sebagai berikut:

(a) pada lajur 1 persamaannya adalah $Y=0,709+2,656 X_{1}+11,645 X_{2}$ dengan koefisien determinasi 0,6 ;

(b) pada lajur 2 persamaannya adalah $Y=0,033+1,892 X_{1}+11,368 X_{2}$ dengan koefisien determinasi 0,7 ; 
(c) pada lajur 3 persamaannya adalah $Y=1,926+2,105 X_{1}+10,792 X_{2}$ dengan koefisien determinasi 0,6 ;

(d) pada lajur 4 persamaannya adalah $Y=0,020+1,301 X_{1}+8,021 X_{2}$ dengan koefisien determinasi 0,7 .

4. Berdasarkan hasil perhitungan didapatkan panjang antrian maksimum sebesar 78,072 meter dengan tundaan 89,826 detik. Panjang antrian minimum yang didapatkan sebesar 9,805 meter dengan tundaan sebesar 15,185 detik.

\section{DAFTAR RUJUKAN}

Departemen Pekerjaan Umum. (1999). Pedoman Perencanaan Jalur Pejalan Kaki pada Jalan Umum. Jakarta: PT. Mediatama Septakarya.

Kementerian Pekerjaan Umum. (2014). Pedoman Kapasitas Jalan Perkotaan. Jakarta: Kementerian Pekerjaan Umum.

Permana, F. (2013). Model Hubungan Antara Tundaan dan Panjang Antrian Kendaraan dengan Lama Penutupan Pintu Perlintasan Kereta Api di Jalan Laswi Kota Bandung. Tugas Akhir - tidak dipublikasikan. Bandung: Jurusan Teknik Sipil, Fakultas Teknik Sipil dan Perencanaan, Institut Teknologi Nasional.

Tamin, O. Z. (2000). Perencanaan dan Pemodelan Transportasi. Bandung: ITB. 